\title{
Energetic and Exergetic Analysis of the Low- temperature Heating System in a model library
}

\author{
Farhad Hekmatipour ${ }^{1, *}$, Milad Jalali ${ }^{2}$, Ali Maroufi ${ }^{3}$ and Farzad Hekmatipour ${ }^{4}$ \\ ${ }^{1}$ Departmetn of Hydraulics and Heat Engineering, Don State Technical University, \\ Rostov on Don, 344002, Russia \\ 2Department of Physics, Southeast University, Nanjing 211189, China \\ ${ }^{3}$ Faculty of Physics, Semnan University, Sokkan Park, Semnan, 3513119111, Iran \\ ${ }^{4}$ School of Mechanical Engineering, College of Engineering, Islamic Azad University \\ Kashan S, Kashan, Iran
}

Article Type: Article

Article Citation: Farhad

Hekmatipour, Milad Jalali, Ali Maroufi

and Farzad Hekmatipour. Energetic

and exergetic analysis of the low-

temperature heating system in a model

library of Tehran. Indian Journal of

Science and Technology. 2020; 13(05),

587-596. D0l: 10.17485/ijst/2020/

v013i05/147820

Received date: September 27, 2019

Accepted date: 0 ctober 18, 2019

*Author for correspondence:

Farhad Hekmatipour farhad.

hekmatipour@gmail.com 9

Department of Hydraulics and Heat

Engineering, Don State Technical

University, Rostov on Don, Russia

\begin{abstract}
Objectives: Energetic and exergetic analysis of the low-temperature heating system in a model library are conducted numerically in this research. Methods: The method of numerical investigation and simulation are employed to compute the energetic and exergetic analysis of the low-temperature heating system in a model library. The use of $\mathrm{C}++$ programming and Hourly Analysis Program software were done the simulation and optimization. The results of this investigation are presented in this article. Findings: Simulation presents that the most of energy which is required for heating is capable to be declined using low-temperature heating system in a model library. It is shown that gas consumption decreases when lowtemperature radiators are applied and the value which is obtained is about $61,458,480 \mathrm{~m}^{3} / \mathrm{yr}$. This means that the performance of the lowtemperature radiation is better than high-temperature radiator and it is about $57,150,000 \mathrm{~m}^{3} / \mathrm{yr}$. The use of low-temperature radiators and high-temperature radiators are compared in this article. The radiator quality factor of the low-temperature radiators and hightemperature radiators are obtained 0.13 and 0.22 , respectively. By using the low-temperature method, radiator quality factor is able to be declined $7 \%$ of the energy efficiency. Based on these cases, using the low-temperature system can be used in some regions in Iran. The economic investigation shows that the IRR is evaluated based on discount $30 \%$, and interest rate $22 \%$ in 20 years. Application and improvement: The declination of energy consumption in building is significant. Therefore, a method which can use to reduce energy consumption is low-temperature heating in winter.
\end{abstract}

Keywords: Low Temperature Heating, Low Temperature Radiator, Heating, Economic evaluation. 


\section{Introduction}

Forty percent of total energy is consumed in household, commercial, and public. As a result, these are important sector which is used final energy such as CNG, Diesel, and electricity. The increment of the energy consumption growth in the building sector is approximately $10 \%$, and it is likely to lead Iran to leave from the Organization of the Petroleum Exporting Countries (OPEC) in a few years later as long as the amount of energy consumption in different sector will remain in the future. Based on Iranian's energy balance, there are 15 million buildings in Iran and average as consumption rate is $30 \mathrm{~m}^{3}$ per square meter of the building in Iran. Whereas, the average gas consumption rate is $5.5 \mathrm{~m}^{3}$ per square meter of the building in European countries which are colder than Iran. According to this report of Iranian's energy balance, domestic and commercial buildings use $30 \%$ of total fossil fuel and $70 \%$ of this use for heating. As a result, energy which is consumed for heating is $20 \%$ of total energy consumption in Iran. In addition, this point should be mentioned that building which are in cold climate regions of Iran use often heating energy, as a consequence, it is possible to diminish the amount of the energy consumption if low energy buildings is built in cold climate region. However, there is much kind of method in the world. While, one kind of building which can be used in cold climate regions. These can thermal comfort and good quality. At first, the district heating (DH) system is used in some buildings which have constructed in Northern European Countries like Sweden. This method applied by many researchers in northern European countries and other regions in the world. These studies are presented as follows:

$\mathrm{DH}$ networks use hot water as heat transfer fluid [1]. The temperature range of the lowheating system was considered between $90^{\circ} \mathrm{C}$ and $120^{\circ} \mathrm{C}$ [1]. Different kind of building use low energy and the capability to reduce demand for primary energy in European buildings [2]. The result of this study shows that $20 \%$ of the energy consumption in European countries can reduce if energy performance of the building is modified or use low-energy building [2]. Low-temperature hot water in a heating system and heat pump is pumped to reduce the amount of energy used in building [3]. In addition, the result of this study was compared by the high-temperature heating system. According this comparison, it was observed that enhancing the coefficient of performance (COP) is almost 2\% [3]. A numerical study on the optimization of a ventilation radiator by several the distribution of vertical longitudinal convection fins is performed [4]. Combination of ventilation air supply and heat emission of to the rooms was used in the system. They also applied higher driving force of air in between the radiator panels compared to traditional radiators.

The result shows that thermal efficiency improves by the low-temperature heating system [4]. A theoretical investigation on energy consumption in five new built semidetached dwellings in Stockholm, Sweden is conducted [5]. They employed lowtemperature heating system combining under-floor heating and ventilation radiators [5]. Exhaust ventilation heat pumps have been gained to preheat supply water for the lowtemperature heating system. In addition, IDA indoor Climate and Energy (ICE) were applied to simulate buildings [5]. New building with low-temperature heating system in term of energy consumption and thermal comfort and to pay some attention to energy saving and indoor air quality are evaluated [5]. The result showed that $23 \%$ of the energy 
was saved in this simulation [6]. A model of emission loss and heat loss of the low temperature heating system and radiators is obtained in European countries which are in the north and central [5]. This research allows creating the building energy simulation model [5]. This model showed that convectional heating losses greater than $50 \%$ of the heating energy were computed in the flats. Based on this model and PI type thermostats and limited heating period distribution and emission losses could reduce energy losses in the building [5].

A new method of the low-energy DH is introduced [6]. The energy demand declined by using low-energy buildings in this research [6]. As a result, 14.3\% of the energy use decreased by these methods [6]. The low-temperature heating method is employed to reduce energy consumption in the buildings [7]. They used the computational fluid dynamic (CFD) and presented the analytical rates of the typical outdoor temperature with the increasing the airflow inside the baseboard heater [7]. A numerical modelling and an experimental measurement for a low-temperature DH are carried out [8]. Using this method, the performance of the building enhances [8]. The result shown it had an important positive effect on writing time for DHW, heat loss, and overall cost [8]. Ventilation and heat emission unit is applied to determine potential for increasing energy efficiency in exhaust-ventilated buildings with warm water heating [9]. They used CFD simulations to confirm an experimental investigation [9]. The error of this experimental study shown that the energy efficiency of ventilation radiators is improved and it is approximately $20 \%$ [9].

The low-temperature heating system is used in typical Danish single-family from 1970s [10]. In this study applied the IDA-ICE software to simulate energy consumption in the house. The result of simulation was compared with the experimental result which achieved, as a consequence, it was determined that temperature reduced in low temperature to reach $60{ }^{\circ} \mathrm{C}$ while it was $68{ }^{\circ} \mathrm{C}$ to $78{ }^{\circ} \mathrm{C}$ in family house [10]. The low exergy system applied and they propose that the low-temperature heating system should be used for buildings [11-12]. This method can help us to use the low valued energy sources. In addition, this system provides comfortable temperature and most of them is clean [13-14].

The low-temperature method is applied to decline heating load in the building [15]. They presented that the simulation results for the combined low-temperature water heating system is compared with those for three convectional radiator and floor heating system [14]. The result illustrated that the performance of the combined low temperature water heating system was good and it was capability to maintain the zone temperature levels [14]. Furthermore, the thermal comfort analysis indicated that the heating system can provide heating energy which is based on Ashrae Standard [14]. The convection and radiation contributions for two temperature levels are calculated [15]. Heat transfer rate is enhanced by using a force convection air velocity component along the radiator surface [15]. Building energy performance with the low energy buildings in Sweden has been evaluated by Building Energy Simulation [16]. A research is done on the controlled by a radiator system which was connected to $\mathrm{DH}$ network since the lowest possible $\mathrm{DH}$ return temperature which can provide heating energy is optimized [17]. They modified the control curve for radiator circuit enabling it consistently to provide an optimal cooling of the DH water [18]. A numerical simulation on the low energy buildings in Sweden is 
carried out [17]. They could reduce $39 \%$ of the energy use originates from the building sectors [19]. They used ESP-r software and CFD-model is applied to simulate airflow [17]. The capabilities in using DH for lower energy houses are studied [20]. They design new model of DH network. The result showed that energy consumption has decreased in the building [19]. Experience's on low-temperature DH in Lystrup - Denmark was done [20]. A new method of a low-energy DH system is designed [22]. This method measured based on substation type and network layouts [21].

This work will be assumed that the majority of the heating energy demand in a model library can be provided by using a low-temperature method. In the beginning, energy need for heating and ventilation system will be computed by hourly analysis program 4.5vs (Carrier Corporation 2012) and non-linear programming. After that, the efficiency of energetic and exergetic will be calculated. The result may be applied in enhancing efficiency of buildings and in decreasing air pollution from domestic, commercial, and public building.

\section{Theory}

Heating load of the radiator is calculated based on fluid temperature. As is flow:

$$
Q_{\text {th }}=1-T_{0} / T(\mathrm{~W})
$$

where $Q$ is thermal load of producing from radiators in $60{ }^{\circ} \mathrm{C}, Q_{\mathrm{n}}$ is heating load which can be produced by each radiator in $60^{\circ} \mathrm{C}, \Delta T$ is the differential supply temperature and return temperature. $\mathrm{M}$ is the specific coefficient for each radiator which is presented based on the manufacture's catalogue.

Exergy is calculated, as in:

$$
\partial E_{\text {inlet }}-\partial E_{\text {outlet }}=\mathrm{d} E_{\text {system }}
$$

where $\partial E_{\text {inlet }}$ is energy which is entered system, $\partial E_{\text {outlet }}$ is energy which is outlet energy, $\mathrm{d} E_{\text {system }}$ is exergy, which is calculated, in the system.

If the energy which pass from the bound of systems, exergy equation is calculated as follows:

$$
\mathrm{d} s=\partial Q / T
$$

where $\mathrm{d} s$ is exergy, $Q$ is differential heating load, $T$ is temperature.

Heating efficiency is achieved as is follow:

$$
\eta_{\mathrm{th}}=1-T_{\mathrm{o}} / T
$$

where $\eta_{\text {th }}$ is exergy efficiency, $T_{\mathrm{o}}$ is outlet temperature, $T$ is inlet temperature.

$$
\delta Q=\delta w-T_{0} \mathrm{~d} s
$$




$$
=-\mathrm{d} U-P_{\mathrm{o}} \mathrm{d} V+T_{0} \mathrm{~d} S
$$

Using integral, equation obtains as is follow:

$$
W=\left(u-u_{0}\right)+P_{0}\left(v-v_{0}\right)+T_{0}\left(s-s_{0}\right)
$$

where $u$ is internal energy, $P$ is pressure, $v$ is volume, $T$ is primary temperature, $s$ is entropy

Equation (7) shows that internal exergy of a closed system is more than zero or it is no longer a minor.

The overall heat transfer is calculated by equation (8):

$$
Q_{\mathrm{h}}=\left(Q_{\mathrm{T}}+Q_{\mathrm{v}}\right)-\left(Q_{\mathrm{s}}+Q_{0}+Q_{\mathrm{e}}+Q_{\mathrm{L}}\right)
$$

where $Q_{\mathrm{h}}$ is heating load of the building, $Q_{\mathrm{T}}$ is heat loss of transmission, $Q_{\mathrm{v}}$ is heat loss of ventilation, $Q_{\mathrm{s}}$ is heat loss of solar heat gain, $Q_{0}$ is heating load which is calculated from occupants and equipment, $Q_{\mathrm{e}}$ is heating load which computed from equipment, $Q_{\mathrm{L}}$ is heating load which is used from lighting.

Radiator surface temperature is calculated from logarithmic temperature. Temperature is computed by the equation (9):

$$
T_{\text {heat }}=\left(T_{\text {in }}-T_{\text {ret }} / 2 \ln \left(\left(T_{\text {in }}-T_{\mathrm{i}}\right)-\left(T_{\text {ret }}-T_{\mathrm{i}}\right)\right)+T_{\mathrm{i}}\right.
$$

where $T_{\text {heat }}$ is logarithmic temperature, $T_{\text {in }}$ is internal temperature, $T_{\text {ret }}$ is water or fluid return.

Radiator factor which is called quality of surface temperature radiator is computed as is follow:

$$
F=1-\left(T_{\text {ref }} / T_{\text {heat }}\right)
$$

According to equations (8) and (9), exergy is obtained as is follow:

$$
E_{\mathrm{x}_{\text {heating }}}=F \times \dot{Q}_{\mathrm{h}}
$$

\section{Case Study Description}

It is mentioned that this work investigates the central library of Islamic Azad University. At first, detail of building needs to simulate the heating and cooling load of the building. As a result, this detail was received from the constructor and then heating and cooling load was calculated. This library was built in a field, which had $6650 \mathrm{~m}^{2}$. In addition, this building constructed on 5 floors and different part of the building which use for various spaces include books, catalogue, offices, Amphitheatre, Website and etc. Furthermore, there have been two under the floor in a model library which used for heating, ventilation and air conditioning and electrical room and main part of the second basement gained for storage 
and workshop. Total area of the building was $35,000 \mathrm{~m}^{2}$ and 25,000 of this area has been ventilated.

The height of floors and ceiling were about $4.6 \mathrm{~m}$ and 3.5, respectively. Moreover, florescent is used for lighting system in a model library. The characteristic of house includes area, area of windows in Table 1. The characteristic of material building, which is used to construct the building, is presented in Table 2 .

The library is located in Tehran with average daily temperature of $17.7^{\circ} \mathrm{C}$. The weather in Tehran is given by the Iran meteorological organization and the weather report of airport organization. Based on these references, the coldest temperature was $-10^{\circ} \mathrm{C}$ on 21 January and the warmest temperature was $36.4^{\circ} \mathrm{C}$ on 22 July 2013.

\section{Method of Design the Low Temperature Building}

The performance of the library and heating ventilation air conditioning system is evaluated by gaining hourly analysis program and non-linear program. The hourly analysis program

TABLE 1. The characteristic of library

\begin{tabular}{ll}
\hline Items & Value \\
\hline Building area $\left(\mathrm{m}^{2}\right)$ & 25,000 \\
Area of windows $\left(\mathrm{m}^{2}\right)$ & 6615 \\
Area of external walls $\left(\mathrm{m}^{2}\right)$ & 10,127 \\
\hline
\end{tabular}

TABLE 2. The characteristic of building material

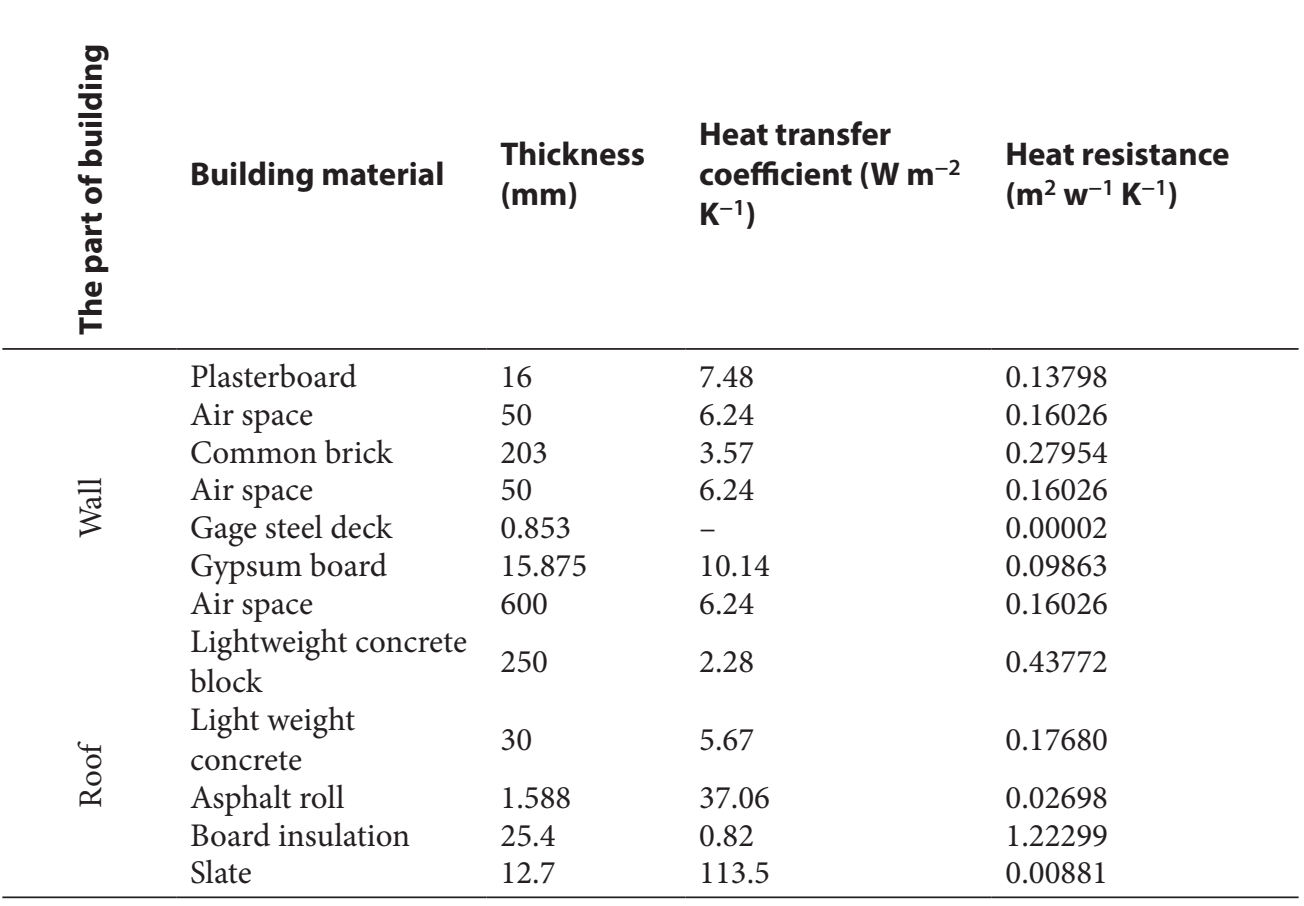


can dynamic simulation with weather dates which is based on the Ashrae standard, simultaneous airflow, and heat transfer rate of wall and windows. This program can be applied to assess the simultaneous performance of all items which require designing the building such as shape, glazing, partition, lighting system, controlling indoor air quality and fresh air, comfort temperature, energy consumption, HVAC system and operating and investing cost and etc. Furthermore, non-linear program is used to develop the model and it also has been employed to calculate all of the cases mentioned before. Moreover, in this research has been applied the energetic and the energetic method because the effect of using low-temperature heating in a model library is achieved. After which the result of the energy calculated for high temperature system compared with the result of lowtemperature system. Thermal comfort is important to provide satisfaction of people since this point is definitely different for everyone, who have various old and sex so that the providing thermal comfort in a different space in the library has been employed standard of Ashrae [22].

\section{Results and Discussion}

It is mentioned that energy consumption in the library is computed by two methods. The result is illustrated in Figure 1. According to Figure 1, it can be observed that gas consumption reduces when low-temperature radiator has been used and it is about $61,458,480 \mathrm{~m}^{3} / \mathrm{yr}$. This means that the performance of the low-temperature radiation is better than high-temperature radiator and it is about $57,150,000 \mathrm{~m}^{3} / \mathrm{yr}$.

Moreover, comfort temperature is calculated by using non-linear programming and exergetic and energetic concept. In high-temperature system, the comfort temperature was $24.2{ }^{\circ} \mathrm{C}$ and the low-temperature system, the comfort temperature was $24.7{ }^{\circ} \mathrm{C}$. Furthermore, it should be mentioned that the efficiency of the energetic and exergetic are investigated in this research. By using the thermal performance achieves based on overall heat transfer internal energy and external into buildings. Furthermore, the quality factor

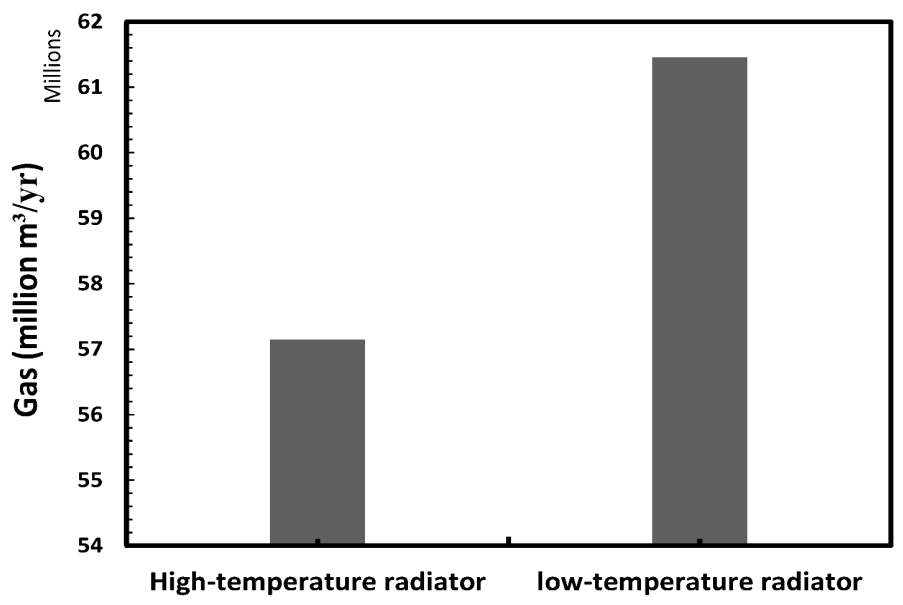

FIGURE 1. Comparison of the gas stimulation before and after simulation. 
of the high-temperature radiators and low-temperature radiators are computed by nonlinear programming. The result is shown in Figure 2.

According to the figure, it can be observed that the radiator quality factor of the lowtemperature radiators and high-temperature radiators are 0.13 and 0.22 , respectively. By using the low-temperature method, it can be reduced $7 \%$ of the energy efficiency. Based on these cases, using the low-temperature system can be used in some regions in Iran.

Based on investing data, economic assessment has been conducted in this study. Investing cost of the low-temperature radiator is \$14511.2 and simple payback time of the using low-temperature radiator has been computed. Whereas, operating cost can reduce and it is about $\$ 2400$. In addition, IRR is evaluated based on discount $30 \%$, and interest rate $22 \%$. IRR obtains 0.04 and therefore payback period is 31 years.

\section{Conclusion}

In this research, the effect of using low-temperature radiators in a model library were investigated by using energtic and exergetic. The results may be summarized as follows:

1. The thermal performance of the heating system is definitely enhanced when the heating system works with the low-temperature because the exergy performance of the low-temperature radiator is lower than high-temperature radiators as a consequence of the energy efficiency should definitely improve or it is led to be saving energy.

2. By using the low-temperature radiator, $4,302,000 \mathrm{~m}^{3} / \mathrm{yr}$ of energy decreases.

3. The quality factor of the low-temperature radiators is lower than the high-temperature radiator and the energy efficiency reduces up to $7 \%$.

4. Exergy performance IRR and payback time are 0.03 and 20.8 year, respectively.

According to the result, using the low-temperature system has been reduced the proportion of the demand for building energy. In fact, the decreases $7 \%$ of total heating

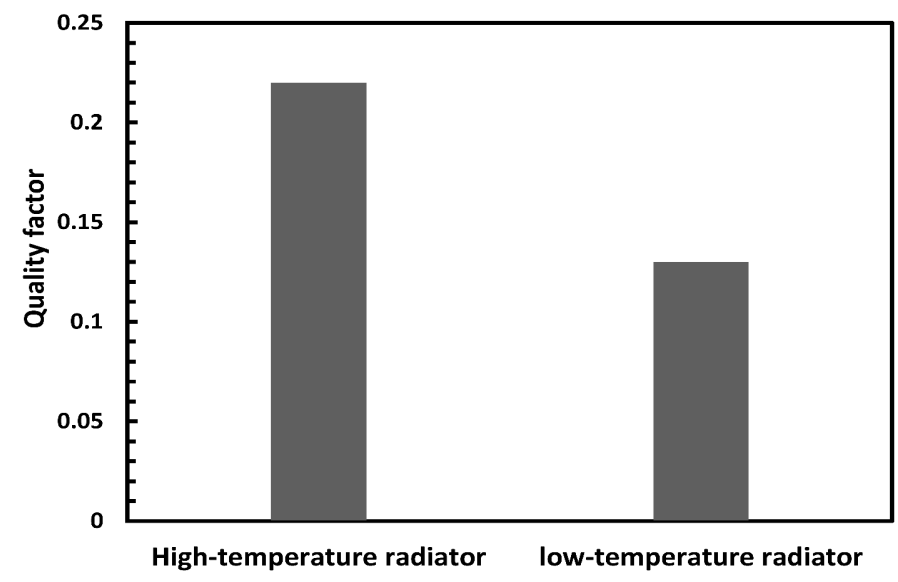

FIGURE 2. Comparison between quality factor of the low-temperature radiators and high-temperature radiators. 
load. In addition, these have the minimum investment return and the result of payback period obtaining these systems.

\section{References}

1. Gadd H, Werner S. Achieving low return temperatures from district heating substations. Applied Energy. 2014; 136, 59-67.

2. Anisimova N. The capability to reduce primary energy demand in EU housing. Energy and Buildings. 2011; 43(10), 2747-2751.

3. Homberg S, Myhren JA, Ploskic A. Low-temperature heat emission with integrated ventilation air supply. In: 10th Rehva world congress on sustainable energy use in buildings. 2010; 257-264.

4. Myhren JA, Holmberg S. Improving the thermal performance of ventilation radiators-the role of internal convection fins. International Journal of Thermal Science. 2011; 50, 115-123.

5. Hesaraki A, Holmberg S. Energy performance of low temperature beating systems in five new built Swedish dwellings: a case study using simulations and on site measurements. Building and Environment. 2013; 64, 85-93.

6. Maivel M, Kurnitski J. Low temperature radiator heating distribution and emission efficiency in residential buildings. Energy and Buildings. 2014; 69, 224-236.

7. Rosa AD, Christensen JE. Low-energy district heating in energy-efficient building area. Energy. 2011; 36, 6890-6899.

8. Ploskic A, Holmberg S. Low-temperature baseboard heater with integrated air supply - an analytical and numerical investigation. Building and Environment. 2011; 46, 176-186.

9. Brand M, Thorsen JE, Svendsen S. Numerical modelling and experimental measurements for a low-temperature district heating substation for instantaneous preparation of DHW with respect to service pipe. Energy. 2012; 41, 392-400.

10. Myhren JA, Holmberg S. Performance evaluation of ventilation radiators. Applied Thermal Engineering. 2013; 51, 315-324.

11. Brand M, Saendsen S. Renewable-based low-temperature district heating for existing buildings in various stages of refurbishment. Energy. 2013; 62, 311-319.

12. Al-Juunsela M. Low-energy systems for heating and cooling of building. ECBCS Annex 37 Summer Report. 2003; 1-5.

13. Heating and cooling with a focus on increased energy efficiency and improved comfort. http:// www.iea-ebc.org/Data/publications/EBC_Annex_37_PSR.pdf. Date accessed: 2010.

14. Hasan A, Kumtiski J, Jokiranta K. A combined low temperature water heating system consisting of radiators and floor heating. Energy and Buildings. 2000; 41, 470-479.

15. Myhren JA, Holmberg S. Flow patterns and thermal comfort in a room with panel, floor and wall heating. Energy and Buildings. 2008; 40(4), 524-536.

16. Molin A, Rohdin P, Moshfegh B. Investigation of energy performance of newly built low-energy buildings in Sweden. Energy and Building. 2011; 43(10), 2822-2831.

17. Karlsson JF, Moshfegh B. Energy demand and indoor climate in a low energy building-changed control strategies and boundary conditions. Energy and Buildings. 2006; 38(4), 315-326.

18. Lauenburg P, Wollerstrand J. Adaptive control of radiator system for a lowest possible district heating return temperature. Energy and Building. 2000; 72, 132-140.

19. Olsen PK, Lambertsen H, Hummelshøj BB, Christiansen CH, Svendsen S, Larsen CT, Worm J. A new low-temperature district heating system for low energy buildings'. In: The $11^{\text {th }}$ international symposium on district heating and cooling. 2008; $1-12$. 
20. Experiences on low-temperature district heating in lystrup- Denmark. https://orbit. dtu.dk/en/publications/expieriences-on-lowtemperature-district-heating-in-lystrup-denmark(6f91408c-7eb6-404e-9c0d-929815f0a8b6).html. Date accessed: 2011.

21. Tol HI, Svedsen S. Improving the dimensioning of piping networks and network layouts in lowenergy district heating systems connected to low-energy buildings: a case study in Roskilde, Denmark. Energy. 2012; 38(1), 276-290.

22. ASHRAE handbook HVAC applications. https://www.academia.edu/22524538/2011_ ASHRAE_HANDBOOK_HVAC_Applications_SI_Edition. Date accessed: 2011. 